\section{In Vitro Mutation Induction of Saintpaulia Using Ethyl Methanesulfonate}

\author{
Jong-Yi Fang ${ }^{1}$ \\ Department of Tropical Agriculture and International Cooperation, National \\ Pingtung University of Science and Technology, No. 1 Shueh Fu Road, Neipu, \\ Pingtung 91201, Taiwan
}

\begin{abstract}
Siguina Traore
Direction de la Vulgarisation et de la Recherche Développement, Direction Générale des Productions Végétales, Ministère de l'Agriculture, de l'Hydraulique et des Ressources Halieutiques, 03 BP 7018 Ouagadougou 03, Burkina Faso
\end{abstract}

Additional index words. adventitious shoots, ethyl methanesulphonate, in vitro mutation, Saintpaulia

\begin{abstract}
This study has been performed to investigate the efficiency of the chemical mutagen ethyl methanesulphonate (EMS) to induce mutations in Saintpaulia. In vitro leaf sections of Saintpaulia cv. Crystobal were exposed to various EMS treatments at $0 \%$, $0.2 \%, 0.4 \%$, and $0.6 \%$ for $30,60,120$, and $240 \mathrm{~min}$ after which adventitious shoots were recovered from the treated explants. Shoots producing at least six leaves were induced to root and the resulting plantlets were transplanted to soil. A total of 1838 plantlets was grown to flowering stage and 10 mutants were identified. Four of the mutants were variegated leaf chimeras and the remaining six presented variations at the level of flower color and/or fringe. Results in the present study showed the efficiency of EMS to induce in vitro mutation of Saintpaulia and the method can be used in the future to assist breeding in this popular ornamental plant.
\end{abstract}

Saintpaulia (family Gesneriaceae), commonly known as African Violet, is a popular houseplant as a result of its compact size, tolerance of shaded conditions, ease of vegetative propagation, and potential to flower year round. To date $\approx 20,000$ varieties have been produced globally by conventional hybridization techniques and spontaneous mutation, and annually, several hundred new cultivars are released (Ghisleni and Martinetti, 1995). The breeding of Sainpaulia is nevertheless hampered by the low number of wild species available for crosses and the low spontaneous mutation frequencies. For commercial floriculture, development of new and improved varieties is important because it will keep up the interest of the consumers. Today, biotechnological approaches (e.g., mutation breeding, genetic transformation) have proved to be a powerful tool to complement the traditional breeding works in many ornamental species.

Mutation breeding has become increasingly popular in recent times as an effective tool for crop improvement, and more than 2250 mutant cultivars have been released worldwide (Ahloowalia et al., 2004). Artificial mutation induction can be carried out using physical and chemical mutagens and mutation induction with radiation was the most frequently used method to develop di-

Received for publication 14 Apr. 2011. Accepted for publication 30 May 2011.

${ }^{1}$ To whom reprint requests should be addressed; e-mail jyfang@mail.npust.edu.tw. rect mutant varieties (Ahloowalia et al., 2004). Several reports on the induced mutation of Saintpaulia using physical mutagens such as ion beam, $\mathrm{x}$-ray, and gamma ray were published in the past (Leenhoots et al., 1982; Wongpiyasatid et al., 2007; Zhou et al., 2006). In these works, although variants were observed in the regenerated shoot population, the procedure required expensive units to operate, which is out of scope for most research and commercial laboratories. Chemical mutagens could be successfully applied to induce mutations where no irradiation facility is available. In some cases, the efficiency of chemical mutagens has proved to be greater than those of physical mutagens (Jacobs, 2005; Rego and Faria, 2001). Among the chemical mutagens, EMS is considered very effective and its effectiveness has largely been demonstrated in cereal crops such as rice (Bhan and Kaul, 2003), wheat (Bozzini and Mugnozza, 2003), and barley (Nicoloff, 2003) as well as in Arabidopsis thaliana (Jacobs, 2005). Recently, this mutagen has also been used to treat seeds and in vitro propagules of many species (Basu et al., 2008; Latado et al., 2004; Luan et al., 2007). To our knowledge, there is no report so far on the EMS use in Saintpaulia; it is therefore our objective to study the possibility of using this mutagen to induce mutations in in vitro-grown Saintpaulia.

\section{Materials and Methods}

Saintpaulia cv. Crystobal is a standardsized cultivar with a rosette growth habit. Its flowers are double ( $\approx 3$ to $4 \mathrm{~cm}$ in diameter), magenta in color, and present a white fringe around the lobes. The leaves are plain green. This cultivar is fast-growing, moderately tolerant to heat so it is popularly sold in warm climate countries such as Taiwan. For the initiation of aseptic culture, young expanding leaves were dissected and washed under running tap water for $5 \mathrm{~min}$ to remove superficial dirt. They were then washed with a detergent solution (consisting of one drop of household detergent in $100 \mathrm{~mL}$ of water) for $10 \mathrm{~min}$. After several rinses with tap water, the leaves were transferred inside a laminar flow cabinet. Surface sterilization of the leaves was carried out with $70 \%$ ethanol for $1 \mathrm{~min}$ followed by $0.5 \%$ sodium hypochlorite disinfection for $10 \mathrm{~min}$; a few drops of Tween-20 were added as a surfactant. Both steps were conducted on an orbital shaker set at $150 \mathrm{rpm}$. The leaves were finally rinsed three to four times with sterile distilled water to remove traces of sodium hypochlorite. Sterilized leaves were cut into $0.5 \mathrm{~cm} \times 0.5$ $\mathrm{cm}$ sections and each section was placed, with its abaxial side touching the medium, in a test tube containing $15 \mathrm{~mL}$ of the African Violet Multiplication (AVM) medium. The AVM medium consisted of full-strength Murashige and Skoog (MS) (Murashige and Skoog, 1962) salts and vitamins, $30 \mathrm{~g} \cdot \mathrm{L}^{-1}$ sucrose, $0.5 \mathrm{mg} \cdot \mathrm{L}^{-1}$ benzyl adenine, 0.1 $\mathrm{mg} \cdot \mathrm{L}^{-1} \alpha$-naphtaleneacetic acid, and $7 \mathrm{~g} \cdot \mathrm{L}^{-1}$ agar. The $\mathrm{pH}$ of the medium was adjusted to 5.7 before sterilization in an autoclave at $121{ }^{\circ} \mathrm{C}, 15 \mathrm{psi}$ for $15 \mathrm{~min}$. The explants were maintained on AVM medium for a total duration of 8 weeks. Induced adventitious shoots were transferred into $175-\mathrm{mL}$ glass jars containing $60 \mathrm{~mL}$ of MS medium devoid of growth regulators for further shoot development. Two months later, leaves were excised from the grown up shoots and cut into $0.5 \mathrm{~cm} \times 0.5-\mathrm{cm}$ sections again and thus initiating a new multiplication cycle. The shoots obtained after several multiplication cycles were then used for the mutation experiment.

EMS is a potential carcinogen so its preparation and handling were conducted inside a chemical fume hood. A 1\% stock solution of EMS was first prepared using distilled water. This stock solution was then used to prepare $0 \%, 0.2 \%, 0.4 \%$, and $0.6 \%$ EMS solutions using $0.1 \mathrm{M}$ phosphate buffer (pH 7.2). The various EMS solutions were filter-sterilized (through a $0.2-\mu \mathrm{m}$ membrane) before use. Leaf sections measuring $\approx 0.4 \mathrm{~cm} \times 0.4 \mathrm{~cm}$ were immersed in $0 \%$, $0.2 \%, 0.4 \%$, and $0.6 \%$ EMS solutions for 0 , $30,60,120$, and $240 \mathrm{~min}$ with constant swirling throughout the treatment. After the treatments, the explants were rinsed three times with sterile distilled water and blotted dried on a sterile filter paper. They were plated on AVM medium for shoot regeneration. The frequency of explant survival was recorded at Week 4 and the frequency of explants producing shoots was observed at both Weeks 4 and 8 after EMS application. Explants were considered alive if they 
exhibited any kind of growth. The EMS experiment was arranged in a completely randomized design. There were 20 leaf explants per treatment and the experiment was conducted twice. Data were subjected to analysis of variance (Version 9.0; SAS Institute Inc., Cary, NC) and treatment means were ranked according to Duncan's multiple range test and difference tested at $5 \%$ probability.

By the end of the eighth week, regenerated shoots were transferred onto plant growth regulator-free MS medium and the subculture was conducted every $30 \mathrm{~d}$. Two months later, the in vitro plantlets were acclimatized and grown in a pre-sterilized substrate composed of peat, vermiculite, and perlite at a ratio of 1:1:1. Selection of mutants was conducted at the flowering stage of the plants. All the cultures (i.e., in vitro and acclimatized plantlets) were maintained at $25 \pm 2{ }^{\circ} \mathrm{C}$ with a 16 -h photoperiod provided by $40 \mu \mathrm{mol} \cdot \mathrm{m}^{-2} \cdot \mathrm{s}^{-1} \cdot \mathrm{L}$ cool white fluorescent lamps.

\section{Results}

Early response of the leaf explants to EMS can be detected within 1 week after the treatments. Some explants shriveled and started to turn brown. However, in other cases, the explants started to swell and expand in size. Observation at a later date indicated that those explants that lost their green appearance were not capable of shoot regeneration, whereas the remaining green explants were all competent to shoot initiation within 4 weeks of EMS exposure. In this case, the shoots were observed to arise directly from the cut edges and on the adaxial side of the explants without an intervening callus phase.

For the $0.2 \%$ EMS treatments, there was no significant difference between the different treatment durations in terms of explant survival; nearly $100 \%$ of explants survived the treatments (Table 1). A similar survival rate was recorded for the $0.4 \%$ EMS treatments for 30,60 , and $120 \mathrm{~min}$. However, a significantly lower survival rate was observed when the explants were treated for $240 \mathrm{~min}$ (e.g., $85 \%$ ). With the $0.6 \%$ EMS treatments, there was a gradual reduction in the survival rate of the explants as the duration of EMS exposure increased. No survival was recorded when the leaves were treated for more than $120 \mathrm{~min}$. It was interesting to see that the frequency of shoot formation recorded at Week 8 coincided with the frequency of explant survival at Week 5. This indicated that the surviving explants were all capable of producing shoots as stated previously.

Shoots were progressively separated from the leaf sections and transferred to growth regulator-free MS medium for elongation and rooting. A total of 1849 in vitro plantlets went through acclimatization, and only 11 shoots died during the process $(91.3 \%$ survival rate). Plantlets were raised to flowering stage and a total of 10 mutants with distinct leaf and flower morphology were identified (Table 2). Among the 10, four mutants were derived from the $0.2 \%$ to $60 \mathrm{~min}, 0.2 \%$ to $240 \mathrm{~min}$, $0.4 \%$ to $60 \mathrm{~min}$, and $0.4 \%$ to $120 \mathrm{~min}$ EMS treatments and they all exhibited variegated foliage (Fig. 1A-D). The remaining six mutants were obtained from the $0.4 \%$ to $30 \mathrm{~min}$ and $0.4 \%$ to $120 \mathrm{~min}$ EMS treatments and they either showed variations in flower color (i.e., different shades of purple, pink, red-purple) and/or in the white fringe around the lobes (i.e., presence, absence) (Fig. 1E-J). Unlike the leaf mutants, the flower mutants were all phenotypically uniform.

\section{Discussion}

The global flower industry thrives on novelty and traits such as flower color, form, size, and scent are primary novelty markers because they are key determinants in consumer choice of ornamental plants (Datta and da Silva, 2006). For Saintpaulia, a species that is mostly appreciated for its flowers, continuous production of new cultivars with original flower colors and forms is important

Table 1. Frequency of leaf explant survival and shoot regeneration after different EMS treatments.

\begin{tabular}{ccccc}
\hline \multicolumn{2}{c}{ EMS treatment } & & \multicolumn{2}{c}{ Shooting (\%) } \\
\cline { 5 - 6 } $\begin{array}{c}\text { Concn } \\
(\%)\end{array}$ & $\begin{array}{c}\text { Duration } \\
(\text { min })\end{array}$ & $\begin{array}{c}\text { Survival } \\
(\%)\end{array}$ & $\begin{array}{c}4 \\
\text { weeks }\end{array}$ & $\begin{array}{c}8 \\
\text { weeks }\end{array}$ \\
\hline 0 & 0 & $100^{\mathrm{a}}$ & $57^{\mathrm{bc}}$ & $100^{\mathrm{a}}$ \\
0.2 & 30 & $100^{\mathrm{a}}$ & $80^{\mathrm{a}}$ & $100^{\mathrm{a}}$ \\
& 60 & $97.5^{\mathrm{a}}$ & $50^{\mathrm{bc}}$ & $97.5^{\mathrm{a}}$ \\
& 120 & $100^{\mathrm{a}}$ & $35^{\mathrm{c}}$ & $100^{\mathrm{a}}$ \\
& 240 & $100^{\mathrm{a}}$ & $43^{\mathrm{bc}}$ & $100^{\mathrm{a}}$ \\
0.4 & 30 & $100^{\mathrm{a}}$ & $55^{\mathrm{bc}}$ & $100^{\mathrm{a}}$ \\
& 60 & $100^{\mathrm{a}}$ & $50^{\mathrm{bc}}$ & $100^{\mathrm{a}}$ \\
& 120 & $100^{\mathrm{a}}$ & $63^{\mathrm{ab}}$ & $100^{\mathrm{a}}$ \\
& 240 & $85^{\mathrm{b}}$ & $45^{\mathrm{bc}}$ & $85^{\mathrm{b}}$ \\
& & & & \\
& 30 & $90^{\mathrm{ab}}$ & $60^{\mathrm{ab}}$ & $90^{\mathrm{ab}}$ \\
& 60 & $55^{\mathrm{c}}$ & $10^{\mathrm{d}}$ & $55^{\mathrm{c}}$ \\
& 120 & $0^{\mathrm{d}}$ & $0^{\mathrm{e}}$ & $0^{\mathrm{d}}$ \\
& 240 & $0^{\mathrm{d}}$ & $0^{\mathrm{e}}$ & $0^{\mathrm{d}}$ \\
\hline
\end{tabular}

Means in each column followed by the same letter are not significantly different by Duncan's multiple range test at the $5 \%$ level.

EMS = ethyl methanesulphonate. to maintain its economic interest. Although Agrobacterium-mediated transformation of Saintpaulia has been attempted (Mercuri et al., 2000), genetic engineering is still a relatively expensive technique. Mutation breeding, which leads to altered phenotypes after permanent heritable change in the structure of the genetic material (Rego and Faria, 2001), is now established as a time-saving and inexpensive approach for flower improvement (Datta and da Silva, 2006). The present study explores the possibility of adopting mutation breeding in generating new Saintpaulia cultivars.

Chemical mutagens have been applied to numerous plants to induce mutations. For instance, Kohleria internodes treated with $\mathrm{N}$-nitroso-N-methylurea have resulted in a mutant with shorter internodes and smaller leaves (Geier, 1989). Two cultivars of Ipomoea purpurea treated with EMS, N-methyl$\mathrm{N}$-nitro-N-nitrosoguanidine and $\mathrm{NaN}_{3}$, showed corolla whorl-specific characteristics (Bhate, 2001). Rodrigo et al. (2004) obtained chrysanthemum mutants with various petal colors (i.e., pink-salmon, light pink, bronze, white, yellow, and salmon) by means of EMS treatment. However, the low penetration into vegetative tissues of chemical mutagens is a major concern in chemical mutagenesis because this might lead to low mutation efficiency and difficulties in reproducing the experiment (Van Harten, 1998). This problem can nevertheless be circumvented by performing in vitro mutagenesis in which mutations were reported to occur more uniformly compared with the in vivo treatments (Constantin, 1984). The present study showed that the diffusion of EMS into Saintpaulia leaves was successful as evidenced by the gradual loss of explant viability with increasing EMS exposure and concentration. The EMS concentrations used in the present study were hence effective in inducing mutations in Saintpaulia, and they were within the range $(0.5 \%$ to $2 \%)$ tested for in vitro mutagenesis of other plants (Latado et al., 2004; Luan et al., 2007).

Table 2. Frequency of plantlets exhibiting morphological variations following different EMS treatments.

\begin{tabular}{|c|c|c|c|c|c|}
\hline \multicolumn{2}{|c|}{ EMS treatment } & \multirow[b]{2}{*}{$\begin{array}{l}\text { No. plantlets } \\
\text { screened }\end{array}$} & \multirow[b]{2}{*}{$\begin{array}{l}\text { No. leaf } \\
\text { mutants }\end{array}$} & \multirow[b]{2}{*}{$\begin{array}{c}\text { No. flower } \\
\text { mutants }\end{array}$} & \multirow[b]{2}{*}{ Mutation (\%) } \\
\hline Concn $(\%)$ & $\begin{array}{c}\text { Duration } \\
\text { (min) }\end{array}$ & & & & \\
\hline 0 (control) & 0 & 94 & 0 & 0 & 0 \\
\hline \multirow[t]{4}{*}{0.2} & 30 & 43 & 0 & 0 & 0 \\
\hline & 60 & 485 & $1(\mathrm{~A})$ & 0 & \\
\hline & 120 & 222 & 0 & 0 & 0 \\
\hline & 240 & 115 & 1 (B) & 0 & 0.87 \\
\hline \multirow[t]{4}{*}{0.4} & 30 & 95 & 0 & $2(\mathrm{FG})$ & 2.11 \\
\hline & 60 & 158 & $1(\mathrm{C})$ & 0 & 0.63 \\
\hline & 120 & 277 & 1 (D) & 4 (HJKL) & 1.81 \\
\hline & 240 & 84 & 0 & 0 & 0 \\
\hline \multirow[t]{2}{*}{0.6} & 30 & 162 & 0 & 0 & 0 \\
\hline & 60 & 103 & 0 & 0 & 0 \\
\hline
\end{tabular}

The letters within the parentheses refer to the code used for the mutant plant.

EMS = ethyl methanesulphonate. 

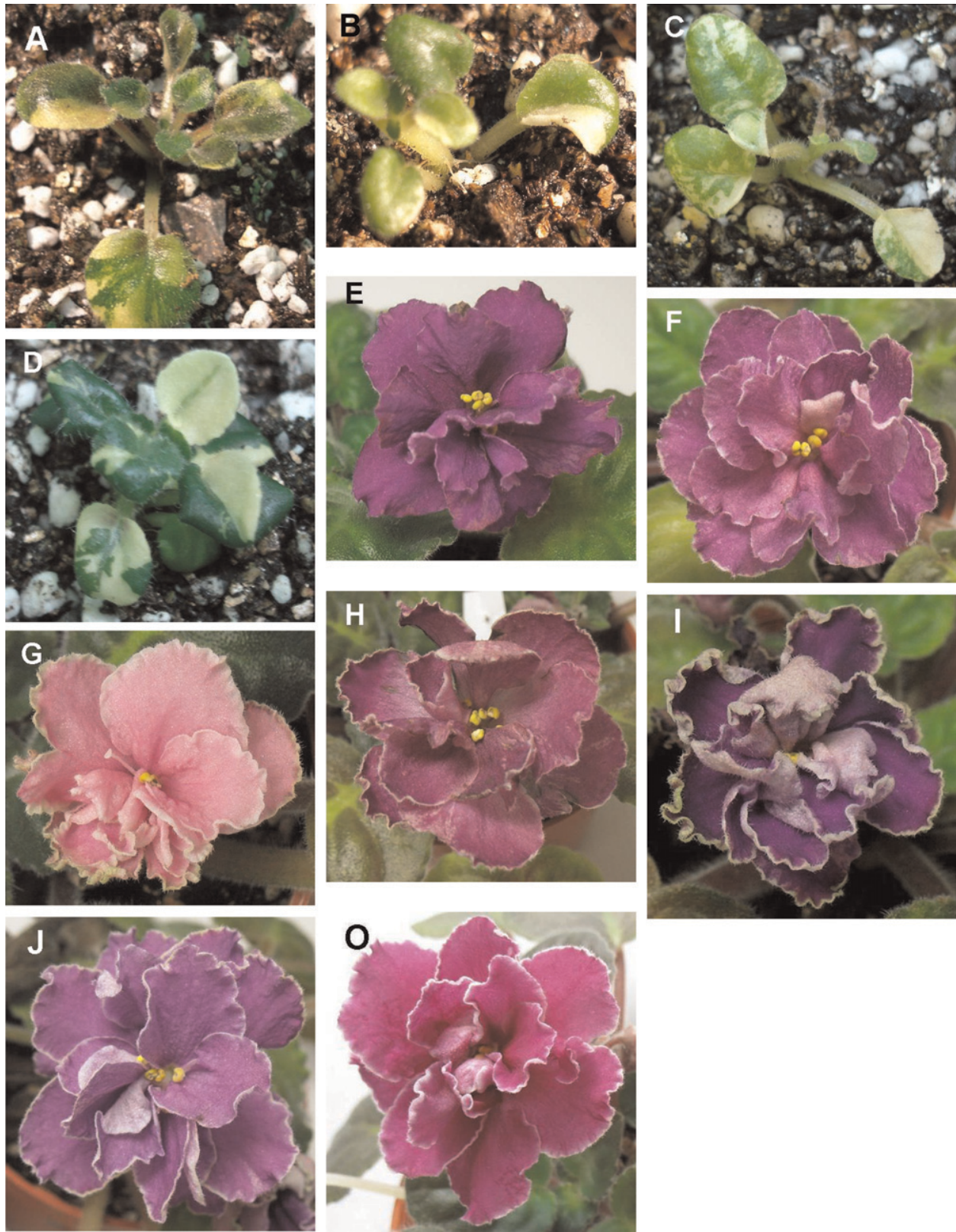

Fig. 1. Saintpaulia mutants obtained following various EMS treatments. (A-D) Chimeral leaf mutants from the $0.2 \%$ to $60 \mathrm{~min}, 0.2 \%$ to $240 \mathrm{~min}, 0.4 \%$ to $60 \mathrm{~min}$ and $0.4 \%$ to $120 \mathrm{~min}$ EMS treatments showed different degrees of leaf variegation. (E-J) Flower mutants from the $0.4 \%$ to $30 \mathrm{~min}$ and $0.4 \%$ to $120 \mathrm{~min}$ EMS treatments differed in petal color and presence/absence of white fringe around the lobes. $(\mathbf{O})$ Control. EMS = ethyl methanesulphonate.

The occurrence of chimeral sectors in Saintpaulia after mutagenesis has been reported previously. Sparrow et al. (1960) observed that one of 154 mutant plants $(0.7 \%)$ regenerated from irradiated Saintpaulia leaf cuttings was chimera. Colchicine treatment to petioles of Saintpaulia leaf cuttings produced one chimeral plant out of $29(3.5 \%)$ (Arisumi and Frazier, $1968)$. In the present study, four of nine (44\%) mutants were chimeral in nature. The occurrence of chimera suggests that the adventitious shoot formation in Saintpaulia might arise from a multicellular origin rather than from a unicellular origin as reported by Broertjes and Van Harten (1985). To stabilize the mutated sector, repetitive vegetative propagation might be necessary. Continuous in vitro tissue culture cycles of variegated adventitious shoots are underway to obtain solid mutants. Besides the chimeral leaf mutants obtained, we have also identified six solid flower mutants. Based on this finding, we propose that $0.4 \%$ EMS treatment for 30 to 120 min could be adopted for the in vitro mutagenic manipulation of Saintpaulia in the future to obtain new mutant cultivars.

\section{Conclusion}

The system described in this study is easy and fast to perform and thus can be implemented in laboratories equipped with standard tissue culture facilities. It is hoped that the in vitro EMS-induced mutations can open up a new approach for the breeding of Saintpaulia.

\section{Literature Cited}

Ahloowalia, B.S., M. Maluszynski, and K. Nichterlein. 2004. Global impact of mutation-derived varieties. Euphytica 135:187-204.

Arisumi, T. and L.C. Frazier. 1968. Cytological and morphological evidence for the single-cell origin of vegetatively propagated shoots in thirteen species of Saintpaulia treated with colchicines. Proc. Amer. Soc. Hort. Sci 93:679-685.

Basu, S.K., S.N. Acharya, and J.E. Thomas. 2008. Genetic improvement of fenugreek (Trigonella foenum-graecum L.) through EMS induced mutation breeding for higher seed yield under western Canada prairie conditions. Euphytica 160:249-258

Bhan, A.K. and M.L.H. Kaul. 2003. Frequency and spectrum of chlorophyll-deficient mutations induced in rice after treatment with radiation and alkylating agents. Mutat. Res. 36:311-317. 
Bhate, R.H. 2001. Chemical induced floral morphological mutations in two cultivars of Ipomoea purpurea (L.). Roth. Sci. Hort. 88:133-145.

Bozzini, A. and G.T.S. Mugnozza. 2003. Relative frequency of chlorophyll to morphological and sterility mutations induced in durum wheat by radiations and chemicals. Mutat. Res. 9:589-597.

Broertjes, C. and A.M. Van Harten. 1985. Single cell origin of adventitious buds. Euphytica 34:93-95.

Constantin, M.J. 1984. Potential of in vitro mutation breeding for the improvement of vegetatively propagated crop plants, p. 59-77. International Atomic Energy Agency (Vienna, Austria). Induced mutations for crop improvement in Latin America, Vienna, Austria.

Datta, S.K. and J.A.T. da Silva. 2006. Role of induced mutagenesis for development of new flower colour and type in ornamentals, p. 640 645. In: Da Silva, J.A.T. (ed.). Floriculture, ornamentals and plant biotechnology: Advances and topical issues. Vol 1. Global Science Books Ltd., Middlesex, U.K.

Geier, T. 1989. An improved type of 'Kohleria' obtained through in vitro chemical mutagenesis. Mutat. Breeding Newslett. 34:7-8.

Ghisleni, P.L. and L. Martinetti. 1995. Saintpaulia, p. 158-266. In: Annali Accademia di Agricoltura di Torino.
Jacobs, M. 2005. Comparaison de l'action mutagen d'agents alkylants et des radiations gamma chez Arabidopsis thaliana. Radiat. Bot. 9: 251-268.

Latado, R.R., A.H. Adames, and A.T. Neto. 2004. In vitro mutation of chrysanthemum (Dendranthema grandiflora Tzvelev) with ethylmethanesulphonate (EMS) in immature floral pedicels. Plant Cell Tiss. Org. 77:103-106.

Leenhouts, H.P., C. Broertjes, M.J. Sijsma, and K.H. Chadwick. 1982. Radiation stimulated repair in Saintpaulia: Its cellular basis and effect on mutation frequency. Environ. Exp. Bot. 22:301-306.

Luan, Y.-S., J. Zhang, X.-R. Gao, and L.-J. An. 2007. Mutation induced by ethylmethanesulphonate (EMS), in vitro screening for salt tolerance and plant regeneration of sweet potato (Ipomoea batatas L.). Plant Cell Tiss. Org. 88:77-81.

Mercuri, A., L. De Benedetti, G. Burchi, and T. Schiva. 2000. Agrobacterium-mediated transformation of African violet. Plant Cell Tiss. Org. 60:39-46.

Murashige, T. and F. Skoog. 1962. A revised medium for rapid growth and bioassays with tobacco tissue cultures. Physiol. Plant. 15:473479.
Nicoloff, H. 2003. Effect of sodium acetate and sodium chloride on EMS-induced chlorophyll mutations in barley. Mutat. Res. 23:57-62.

Rego, L.V. and R.T. Faria. 2001. Tissue culture in ornamental plant breeding review. Crop Breed. Appl. Biot. 1:285-300.

Rodrigo, R.L., H.A. Alvis, and T.A. Neto. 2004. In vitro mutation of Chrysanthemum morifolium (Dendranthema grandifolia). Plant Cell Tiss. Org. 77:103-106.

Sparrow, A.H., R.C. Sparrow, and L.A. Schairer. 1960. The use of X-rays to induce somatic mutations in Saintpaulia. Afr. Violet Mag. 13:32-37.

Van Harten, A.M. 1998. Mutation breeding: Theory and practical applications. Cambridge University Press, London, U.K.

Wongpiyasatid, A., P. Jompuk, K. Chusreeaeom, and T. Taychasinpitak. 2007. Effects of Acute gamma irradiation on adventitious plantlet formation of Saintpaulia ionantha (African violet) detached leaves. Kasetsart J. 41:414-419.

Zhou, L.B., W.J. Li, S. Ma, X.C. Dong, L.X. Yu, Q. Li, G.M. Zhou, and Q.X. Gao. 2006. Effects of ion beam irradiation on adventitious shoot regeneration from in vitro leaf explants of Saintpaulia ionantha. Nucl. Instrum. Methods 244:349-353. 